\title{
TEMPO E ATIVIDADES DE LAZER
}

\author{
Marilia Gomes dos Reis Ansarah *
}

\begin{abstract}
RESUMO: O uso que o homem faz de seu tempo livre e a importância do lazer na civilizaçāo humana. Análise dos fatores dinâmicos do lazer urbano e das atividades de lazer nos centros urbano-industriais.
\end{abstract}

UNITERMOS: Tempo livre: lazer. Lazer: centros urbano-industriais; cotidiano urbano; atividades discricionais.

ABSTRACT: What man does in his free time and the importance of leisure in human civilization. An analysis of dynamic factors of urban leisure and reflections about leisure activities in the urban-industrial centers.

KEY WORDS: Free tine: leisure. Leisure: urban-industrial centers; urban quotidian: discritional activities.

\section{INTRODUÇÃO}

Um problema fundamental na vida das pessoas, principalmente daquelas participantes de sociedades urbano-industriais, $\varepsilon$ mobiliar o tempo livre do lazer.

Nas megalópoles existe uma maior concentraçāo de contradiçōes que põem face a face as diferenças sócio-econômicas e culturais de sua população, provocando efeitos negativos ao homem, quer do ponto de vista psicológico, quer do sociológico. Na verdade, o desenvolvimento acelerado das técnicas de produçāo e o êxodo rural, em busca de mais oportunidades de emprego e de uma "vida melhor", tornaram as urbes lugares de difícil adaptação. De um modo geral,o indivíduo não se realiza no trabalho(fragmentadoe alienado)

(*) Bacharel em Turismo e Mestre em Ciências da Comunicaçāo pela ECA/USP. Supervisora de Cursos da Secretaria Municipal de Cultura, conveniada no Departamento de Relaçōes Públicas, Propaganda e Turismo da ECAJUSP.

End. para corresp.: R. Cláudio, 422 - Água Branca - CEP 05043 - São Paulo - SP Brasil. 
e nem em sua vida social (devido às dificuldades de deslocamento e também de associação). O trabalho atualmente não é meta final portanto, uma das maneiras de o homem buscar a realização do seu $E u$ é através das atividades de lazer.

O tempo cotidiano $e ́$ especificado em um tempo regido pela obrigatoriedade e um tempo dito "livre". É neste último que as definiçōes de lazer consideram a ocorrência de atividades denominadas "discricionais". Como diz Maffesoli: "a vida cotidiana é construída de microatividades, de criaçōes minúsculas, de situaçōes pontuais e totalmente efêmeras". 1

O lazer de hoje não $\varepsilon$ em si o egoísmo nem mesmo o egocentrismo. É, acima de tudo, uma forma nova de afirmação de si próprio, do sujeito social face ao trabalho e às outras instituiçōes de base da cidade.

\section{O HOMEM E O USO QUE FAZ DE SEU TEMPO LIVRE}

Analisando-se o emprego que o homem faz de seu tempo, é possível observar que este tempo pode ser classificado em quatro grandes categorias:

a) tempo de vida natural ou biologica;

b) tempo de trabalho;

c) tempo para obrigaçōes familiares e sociais;

d) tempo livre.

De acordo com essa classificação, o tempo de vida natural ou biológica é aquele dedicado à satisfação das necessidades vitais do homem, ou seja: dormir, alimentar-se, funçōes fisiologicas e de asseio pessoal. O tempo de trabalho é utilizado para as atividades remuneradas destinadas à sobrevivência material. Já o tempo dedicado às atividades familiares e sociais é classificado como aquele tempo situado entre o tempo de trabalho e o tempo livre. Finalmente, o tempo livre é o tempo empregado para desfrutar do lazer, ou seja, o tempo dedicado ao descanso, à distração, ao entretenimento, ou, mesmo, às atividades para aumentar o conhecimento.

Munne $e^{2}$ assinala que o tempo livre pode ser definido como " $a$ quele tempo do indivíduo que é sentido como livre, ao dedicar-se a atividades autocondicionadas de descanso, recreação e criação para compensar-se, e, em última análise, para afírmar-se como pessoa sob o ponto de vista individual e social".

86
O tempo livre do qual o homem dispōe para desfrutar do laze também pode ser dividido, segundo Acerenza, ${ }^{3}$ em três categorias:

a) tempo livre após o trabalho;

b) tempo livre de fim de semana;

c) tempo livre de férias.

Obviamente é muito difícil a uma pessoa dedicar seu tempo livre após o trabalho para fazer turismo, pois este exige um deslocamento e uma permanência fora de seu lugar habitual de residência. Mas, nada impede que esta mesma pessoa possa desfrutar de seu tempo livre por meio de distraçōes, entretenimentos e/ou atividades para aumentar seu conhecimento, como assistir televisão, ir a concertos, cinema e teatro, ouvir música, praticar algum tipo de esporte, dedicar-se à leitura ou outras atividades, como, por exemplo, as produzidas pelos Centros Culturais. ${ }^{4}$

No caso do tempo livre de fim de semana, pode-se optar entre a recreação (clubes, parques) e o turismo (viagens a uma segunda residência no campo ou na praia, hotéis, camping etc.).

Com relação ao tempo livre de férias, pode-se dedicar, entre outras atividades, à prática de turismo. O consumo do lazer em viagem é uma maneira de escapar, temporariamente, às agressōes das urbes industriais, como também ampliar o "horizonte" de conhecimento. Portanto, o turismo pode ser caracterizado como uma das expressōes de lazer que possuem um tempo livre de duração prolongada.

Nesse sentido, considera-se tempo livre como aquele tempo do qual dispōe o indivíduo fora de suas necessidades inevitáveis e obrigaçōes profissionais, familiares, sociais e cívicas, nāo se confundindo com o tempo desocupado dos desempregados, aposentados ou inválidos, para realizar atividades discricionais, ou seja, conforme sua livre escolha, caracterizado por um tempo "ganho" após as atividades laborais.

O tempo dos desempregados, aposentados ou inválidos não é considerado tempo livre, pois não está em estreita relação com a estrutura produtiva de uma sociedade industrial, não se apresentando como "troca" após as atividades laborais. O trabalho cumpre a função de proporcionar a satisfação das urgências vitais, para que os indivíduos possarn, depois, usufruir de uma proveitosa vida de tempo livre, desenvolvendo a personalidade integral, física e mental. 


\section{A IMPORTÂNCIA DO LAZER NA CIVILIZAÇÃO HUMANA}

O reconhecimento da importância do lazer na civilizaçāo humana remonta a muitos séculos. Na Bíblia, já estava destinado um dia por semana, o sábado, ao descanso, ao não-trabalho.

$\mathrm{Na}$ Grécia, o ócio era privilégio de algumas camadas da populaçāo, que valiam-se de escravos para não ter trabalho indigno a fazer. 5 Para o homem grego, o 6́cio nāo significava estar ocioso no sentido de não fazer nada, mas implicava operaçōes de natureza intelectual e espiritual que se traduziam no exercício da contemplação da Verdade, do Bem e da Beleza, de forma não-utilitária. Assim visto,

- ócic seria a atividade de percep̧̧ão receptiva, de inversão intuitiva e contemplativa do ser, uma uniäo das faculdades que os fiĺsofos medievais denominam como ratio $e$ intelectus, entendendo o primeiro como a faculdade responsável pelo pensament discursivo, pela reflexão, e o segundo como a capacidade do simples intuir, da pura visaao intelectual. Pode-se, entäo, dizer que o significado do ócio grego é uma atividade mental em que atuam, de forma integrada, tanto as faculdades superiores do ser humano como as da sensibilidade. 6

No século XVIII, a máquina a vapor marcou a revolução social e econômica, e grandes transformaçōes ocorreram na vida do homem, que agora trabalha fora de casa, em fábricas; tem seu tempo marcado pelo relógio e não mais pela oposição dia/noite.

A evolução tecnológica que se seguiu e que avança devastadoramente ainda em nossos dias, o fracionamento do trabalho, a distância entre o operário (simples peça do processo produtivo) e o produto final, a evoluçāo urbana, a verticalizaçāo das cidades e a reduçāo dos espaços conduziram a problemas típicos da sociedade urbano-industrial que se instalou: perda de identidade do indivíduo (aparece como um número no cadastro do imposto de renda, ou um número de cartão de ponto na indústria), limitaçōes das relaçōes pessoais, perda de espaço vital (enclausuramento em cubículos, chamados apartamentos), ritmo acelerado de vida, afastamento do meio ambiente natural, concorrência em diversos níveis (profissional, pessoal etc.). Tudo isso levou o homem atual a um estado de espírito de constante tensāo, irritabilidade, nervosismo, insatisfação, solidāo, depressāo, sendo os símbolos do nosso século as chamadas doenças psicossomáticas e cardíacas.

Aliados à nova organizaçāo do trabalho, surgiram os sindicatos e outras instituiçōes que conseguiram, entre outras coisas, a reduçāo 88 da jornada de trabalho, as férias remuneradas, a regulamentaçāo da aposentadoria.... A tecnologia também prestou serviços à medicina e graças a métodos e drogas cada vez mais modernos, foi possível a diminuição da mortalidade è uma extensão do tempo médio de vida.

Todos esses fatores levaram, conseqüentemente, a um aumento do tempo livre, surgindo o lazer como compensação dos esforços e penalidades que forman a essência da vida produtiva do ser humano.

\section{FATORES DINÂMICOS E PRODUTORES DO LAZER URBANO}

O crescimento não-equilibrado das grandes cidades industriais, além de provocar uma série de imperfeiçōes, deficiências e modificaçōes na vida social, deixou de considerar, principalmente, o problema do lazer, não obstante sua incontestável relevância.

Conseqüência natural da expansāo industrial das grandes concentraçōes urbanas é o desenvolvimento das atividades do setor terciário ou setor pós-industrial. A sociedade pós-industrial foi qualificada de científico-técnica, cibernética, neotécnica, eletrônica; ou, ainda, a chamada sociedade de consumo, da instrução em massa, da revolução sexual, dos conflitos de geraçōes. É uma sociedade marcada, em primeiro lugar, pelo estado de desenvolvimento avançado das forças produtivas (máquinas, organizações, qualificação da mãode-obra), favorecendo os mais avançados níveis de produçāo ativa, cuja maioria não se encontra nem no setor agrário nem no setor industrial, mas no setor de serviços.

Com a conquista de mais tempo livre, fortemente apoiada pelos movimentos sociais, sobretudo pelo movimento sindical, que já existe há um seculo e meio, tem-se a paulatina reduçāo do tempo de trabalho: a redução do dia de trabalho e da semana de trabalho, com o fim de semana remunerado; a redução do ano de trabalho, com o período de férias pagas; a redução da "vida" de trabalho com o adiantamento da idade da aposentadoria. Esse movimento sindical se reforçou, nos últimos anos, especialmente com o movimento da juventude. Os jovens aceitam cada vez menos que o seu tempo seja "contestado" pela escola, famnlia ou igreja. Há uma inspiração para a autogestão desse tempo livre, segundo seus próprios costumes, sua propria maneira de viver. Atualmente e no mesmo sentido, surgiu um outro movimento social, o da terceira idade, não aceitando que seu tempo seja totalmente absorvido pela utilidade da famnia, e rei- 
vindicando suas próprias atividades, seus próprios clubes. Pode-se acrescer, ainda, os movimentos feministas.

Tais movimentos sociais fazem prever um aumento e uma valo rização do lazer após o trabalho profissional, escolar ou doméstico. Como diz Dumazedier:

O lazer é mais profundamente uma condiçâo para "usar" o tempo de viver. É a as piraçäo ao direito de viver-para-viver sem interdependência com as normas legít mas do dever-ser ọue a produçäo das coisas e a solidariedade dos homens ìnpäem.

O tempo de viver-para-viver valoriza o "caminhar sem rumo" Não se trata fatalmente da "degenerescência" da individualidade em egocentrismo e em excentricidade segundo a palavra de Riesman. 8 É verdade que isso possa acontecer, mas uma função mais freqüente e importante do lazer é uma tentativa para se "desligar" temporariamente da tutela comum do dia-a-dia e das instituiçōes, organizaçōes, agrupamentos, aos quais cada um está ligado pelo seu nascimento, séu estatuto. Não é para romper com esses elos, é para se libertar periodicamente de sua rotina, de seus estereótipos, de seus dogmas. $\mathrm{O}$ lazer é viver temporariamente com o produto da imaginação - é o homem imaginário que Morin ${ }^{9}$ analisa pela projeção e identificação em cenas de cinema. A prática do lazer pode estender este espaço imaginário da arte, do sonho ou da mágica. Permite viver alguns instantes desse espaço imaginário, antes de reencontrar o espaço real das redes sociais experimentadas ou escolhidas de sua identidade social.

Após o caminhar sem rumo, mais ou menos longo, mais ou menos transgressor ou respeitador das regras do jogo, mais ou menos transparente ou velado, vem o "retomo" às necessidades e obrigaçōes da vida cotidiana.

Diante deste caminhar sem rumo, o lazer é um modo de expressão mais completa de si, pelo corpo, os sentidos, os sentimentos, a imaginação, o espírito: é o tempo em que o homem "se esparrama" (segundo a forma publicitária de certas cidades balneárias) sob o sol temporário, numa nudez inabitual. Uma vitalidade contínua na vida comum extravaza em atividades mais livres e extensas do corpo. $\mathrm{O}$ que era censurado pelas conveniências tende a se exprimir com mais simplicidade; o decoro em época de férias ou fins de semana não tem as mesmas regras que na vida comum do tempo de trabalho:

É no mundo do lazer onde os mitos de Dionísio, de Eros, de Narciso, das Sereias ou das Três Graças se reinvestiram para dar a certas práticas efetivas da noite, dos fin de semana ou das férias, uma carga poética tāo mais forte, que estas práticas duram o tempo de um intervalo de lazer entre dois tempos sociais da vida do dia-a-dia que se impóe. Nunca o repetiremos suficientemente. (Dumazedier ${ }^{10}$ )

\section{ATIVIDADE DE LAZER NOS CENTROS URBANO-INDUSTRIAIS}

O fundamento da cultura pós-moderna é a participação do espaço, é a superação do individualismo, é estar junto - o coletivo. $O$ espaço é a concentração do tempo. Segundo Maffesoli: Seria mais prudente seguir os meandros das paixões e dos sentimentos coletivos que
nāo se verbalizam nas clássicas declaraçoes, mas que se exprönem numa prática, ds
vezes banal, mas que marca profundamente o corpo social. É possivel que tal con-
senso delinite a logica do "ser-junto" que se esboça em nossos dias, logica que nāo
seria mais finalista, voltada para o futuro, mas, ao contrário, o que exige de algum
modo um pensamento de "doméstico". (...) É essa socialidade, fundamento do "ser
junto", que obriga a considerar tudo que se tinha convencionado tomar como es-
sencialmente frivolo, anedótico ou sem sentido ll.

Todos os pequenos fatos do cotidiano tornam-se constantes da vida contínua. Os grupos, as pequenas comunidades, as redes de afinidades ou de vizinhança se preocupam com relaçōes sociais próprias, como o ambiente social e, certamente, com o meio ambiente natural. É no próximo, no insignificante, o que escapa à finalidade macroscópica, que se exerce o domínio da "socialidade".

Por tudo que foi descrito pode-se pensar em quais são as atividades de lazer nos centros urbano-industriais. $O$ lazer pode assumir a forma de um passeio a pé, ginástica, jogos, leitura de um livro, ir ao cinema, teatro, ouvir música, cuidar de plantas, "bater papo" com amigos, aprimorar-se em alguma coisa, viajar, entre outros. Tudo sem se ater a nenhum tipo de obrigação, desenvolvido dentro de determinados locais que a pessoa escolhe para viver tais valores.

Porém, desde que o homem conseguiu a "façanha" de separar o trabalho do lazer, cada vez mais ele sente dificuldade de viver o trabalho como trabalho e o lazer como lazer, caracterizando dois tipos básicos de comportamento:

a) os "fanáticos" pelo trabalho;

b) os "amantes"do lazer. 
Considerando essas duas colocaçöes como antíteses, os fanáticos pelo trabalho são aqueles que após oito horas diárias de trabalho ou mais, em seu tempo livre não conseguem se desligar: levarn atividades para casa, ou quando saem, o fazem somente com amigos de profissão.

De acordo com o sociólogo Lima Camargo, não importa o clima, a estação ou o ponto geográfico; seja no Rio de Janeiro, em Paris ou Londres,

a pesquisa orçamenio-tempo - que estuda simultaneamente em vários países como as pessoas gastam o seu tempo, dentro de um universo dos 1440 minutos diários e as pessoas gastam o seu tempo, dentro de um universo dos 1440 minutos diarios
168 horas semanais, de inaivíduos entre 18 e 65 anos - provou que $72 \%$ do tempo livre é passado dentro de casa. A proporçāo é a seguinte: $36 \%$, televisāo, $11 \%$, outras formas de lazer associadas à indústria de cultura (livros, discos, jornais, rádio, entre outros) e 25\% de tempo é dedicado a conversas, recebimento de amigos e telefonemas. A proteçāo, o acolhimento, o dománio do espaço, a previsibilidade de situaçōes e a casa como sónioblo maior do "eu" sāo as possíveis explicaşōes.

Não são poucas as pesquisas que mostram a tendência cada vez mais acentuada das pessoas em desenvolver atividades dentro de casa no seu tempo livre, como cozinhar, lavar carro, cuidar de animais, pintar a casa, consertar aparelhos domésticos, assistir a um filme em vídeo, visitar amigos ou mesmo gozar horas de preguiça como apenas dormir..

Para os jovens, os "shoppings" ganham, a partir de sábado à tarde, características e um público completamente diferente, cuja última preocupação é o consumo, transformando o espaço em local de encontro e "badalaçōes", seja apenas para circular, exibir-se nas pistas de patinação, ouvir música na discoteca "Hi-Fi", ir ao cinema, comer no "McDonald's", ou encontrar a turma para animados "bate-papos".

De acordo com o antropólogo Frúgoli Jr. em sua dissertação de mestrado, 12 "nos 5 (cinco) maiores shoppings de São Paulo (Eldorado, Iguatemi, Ibirapuera, Center Norte e Morumbi), circulam 11 milhōes de pessoas mensalmente (dados de 1988), sendo que, de uma maneira geral, nesses espaços convivem várias formas de comportamento". Seja como for, funcionam, na verdade, como fortes pólos de lazer.

Fourastié, na década de 70 , arriscou algumas previsões no livro As 40 mil horas para o ano 2005 :

Os trabalhadores terāo uma jornada de 30 horas semanais, três meses de férias aposentadoria aos 25 anos de trabalho. Neste esquema, o tempo de lazer se sobreporia ao de trabalho e ai todos se sentiniam ralvez mais à vontade para o "lux" poria ao de trabalho e at dodos se sentinam talvez mais a vontade para o "luxo"

\section{CONSIDERAÇŌES FINAIS}

As atividades de lazer que mobilizam o tempo livre podem ser, acima de tudo, uma forma de afirmação de si próprio, do sujeito social em face do trabalho e a outras instituições de base da cidade. Apesar das controversias, pode-se dizer que economizar tempo de trabalho é aumentar o tempo livre. Esse tempo que serve ao desenvolvimento completo do indivíduo, mediante atividades de entretenimento, assim como atividades que têm como finalidade o desenvolvimento global da personalidade, poderá transformar, bem naturalmente, aquele que dele tira proveito num indivíduo diferente...

Além disso, as atividades de lazer proporcionam ao indivíduo uma liberação no tempo de tendências longamente contidas ou reprimidas pelo "peso" do trabalho e instituições normativas; elas vêm sendo lentamente libertadas e desenvolvidas pela conquista social de tempo livre, acompanhando um nível de vida mais elevado, o ponto de permitir uma maior expressão social de si, através do corpo ou da mente, não somente para alguns, mas inegavelmene para todos os trabalhadores.

\section{NOTAS BIBLIOGRÁFICAS}

1. MAFFESOLI, M. - A conquista do presente. Rio de Janeiro : Rocco, 1984, p. 24.

2. MUNNÉ, F. - Psicosociologia do tiempo libre. México : Trillas, 1990, 6 ed., 206 p.

3. ACEREN究: M. A. Administración del turismo. México : Trillas, 1968, p. 31.

4. ANSARAH, M. G. dos R. Política de desenvolvumento na esfera de lazer cultural: estudo de caso do Centro Cultural do Jabaquara. São Paulo : ECA/USP, 1988, 241 p. do de caso do Centro Cult
(Dissertaçáo de Mestrado)

5. Aristóteles (no livro: Política. Madrid : Instituto de Estudios Políticos, 1951, p. 149-53) assinala que nem todas as pessoas deveriam adquirir os conhecimentos úteis, pois havia uma distinção estabelecida entre os trabalhos dignos, dos homens livres e os indignos, dos servos. Eram considerados trabalhos todos os ofícios que deformam o corpo, assim como os assalariados, porque privam a mente do ócio e a degradam.

6. BACAL, S. S. Lazer, teoria e pesquisa. Sāo Paulo : Loyola, 1988, p. 48.

7. DUMAZEDIER, J. Revolution culturelle du temps libre, 1968-1988. Paris : Meridiens Klincksieck, 1988, p. 48

8. REISMAN, D. et al. A multidão solitária: um estudo da mudança do caráter americano. São Paulo : Perspectiva, 1971, 396 p. (Debates, Ciências Sociais, 41) 
9. MORIN, E. Cultura de massa no século XX: o espírito do tempo. Rio de Janeiro : Forense, 1969, 2 ed., p. 16-20.

10. DUMAZEDIER, J. Obra citada, p. 51.

11. MAFFESOLI, M. Socialidade é a marca da ética p6s-moderna. Folha de S. Paulo. São Paulo, 14 de outubro de 1989, p. 6.

12. FR ÚGOLI JR, H. A prática do lazer nos shoppings de Sāo Paulo. São Paulo: Depto. de Antropologia/USP, p. 52. (Dissertaçāo de Mestrado)

13. FOURASTIÉ, J. As 40 mil horas. Rio de Janeiro: Forense. 1967. 